\title{
A cidade, o local e o conceito de região a partir da perspectiva pós-colonial
}

\section{The city, the place and the region concept from a post-colonial perspective}

José Ricardo Marques dos Santos ${ }^{1}$

\begin{abstract}
Resumo: O presente artigo pretende discutir como a perspectiva pós-colonial e pósestruturalista permite repensar os conceitos de território, região e cidade. Principalmente por permitir pensar o descentramento de sujeitos invisibilizados pela sociologia e antropologia brasileira clássica. Rompendo com a influência que a sociologia da escola de Chicago exerceu sob as formas de conceber os objetos e experiências etnográficas no Brasil, principalmente através de Florestan Fernandes.
\end{abstract}

Palavras-chave: Cidade. Pós-colonial. Pós-estruturalismo.

\begin{abstract}
This paper intend to discuss how the post-colonial and post-structuralist perspective allows us to rethink the concepts of territory, region and city. Mainly because it allows thinking about the subjects decentralization made invisible by classical Brazilian sociology and anthropology. Breaking with the influence that the sociology of the Chicago school exercised as conceiving ways ethnographic objects and experiences in Brazil, mostly through Florestan Fernandes.
\end{abstract}

Keywords: City. Post-colonial. Post-structuralism.

Este artigo nasce como continuação da reflexão que iniciei no doutorado em sociologia na Universidade Federal de São Carlos sobre as formas pensar e conceituar as experiências dos/das africanas/africanos e seus/suas descendentes no Estado de Minas Gerais, na região conhecida como Triângulo Mineiro durante o século XIX. Pretende-se aqui dialogar com os estudos pós-coloniais e pós-estruturalistas a fim de pensar o conceito de local, território e região à luz destas perspectivas teóricas. Ao mesmo tempo que dialogado com a obra de Florestan Fernandes, sociólogo brasileiro de grande influência na sociologia das relações raciais o Brasil. Em particular dedico-me ao diálogo com teses e dissertações sobre o Estado de Minas Gerais. Principalmente as que abordam tradições culturais de origem afrobrasileiras neste estado.

\footnotetext{
${ }^{1}$ Doutorado em Sociologia pela Universidade Federal de São Carlos. Professor assistente da Universidade Estadual do Sudoeste da Bahia. E-mail: josericardosummers@gmail.com Orcid: https://orcid.org/0000-0003$3477-4728$
}

Sertanias: Revista de Ciências Humanas e Sociais - ISSN: 2763-566X Volume 1, número 1, julho-dezembro de 2020. 
As perspectivas teóricas supracitadas, abriram um novo campo de investigação no Brasil. Principalmente a partir da obra de Franz Fanon, Stuart Hall e Paul Gilroy. Como o descentramento dos sujeitos configura-se como um tema central deste conjunto de autores e autoras, muitas pesquisas passaram a estabelecer uma dialogo crítico com a sociologia brasileira clássica, em especial a conhecida como sociologia das relações raciais. Para os efeitos deste artigo proponho uma reflexão sobre os conceito de local, cidade e região.

É preciso considerar que boa parte dos trabalhos sobre a história do surgimento das cidades $^{2}$ (sobretudo de Minas Gerais) tenha sido feita por memorialistas (SANTOS, 2019). Principalmente porque pesquisas de doutorado e mestrado se dedicarem a outros tipos de problemas, não vendo na história local um objeto, quando muito, estes estudos diluem a história local na história nacional ${ }^{3}$. No caso de Minas Gerais é possível encontrar toda uma série de historiadores do século XIX que buscaram compreender como os agrupamentos urbanos neste estado surgiram (SANTOS, 2019) ${ }^{4}$. Não obstante, como a visão sobre a história e a sociologia mudou a partir da década de 1940, estes estudos são poucos citados e discutidos hoje. Esta mudança ocorre a partir do impacto das obras de Florestan Fernandes e Roger Bastide, dois sociólogos centrais para a estruturação do campo da sociologia o Brasil.

Contudo, conforme argumenta Cota (2013), é possível pensar que Minas Gerais configura-se como um problema para a sociologia de grandes proporções. Em específico porque possui diversas regiões com trajetórias históricas muitos diferentes, pois suas divisões territoriais se relacionam com intrincadas dinâmicas políticas, sociais e culturais próprias. Por conseguinte, podemos pensar que possuem projeções sobre si mesmas de elementos culturais. Seria possível partir do pressuposto que há a invenção de uma história/narrativa que torna possível uma comunidade imaginada local (ANDERSON, 2005). Uma vez que as narrativas de origem das cidades se apresentam como formas de imaginação ${ }^{5}$.

Neste sentido, as características que Benedict Anderson (2005) percebe na constituição das nações, enquanto construções discursivas, poderiam servir para pensar em

\footnotetext{
${ }^{2}$ A sociologia urbana tratou de captar as relações sociais entre diversos grupos dentro de um contexto histórico limitado. Pensando/privilegiando o momento presente. Muito por ser influenciada pela sociologia compreensiva de Max Weber (HIRATA, 2010).

${ }^{3}$ Ver Schwarcz (1987; 1998) e Schwarcz \& Starling (2015).

${ }^{4}$ Cito nominalmente Borges Sampaio (1971) como exemplo. O mesmo teve seus trabalhos reconhecidos pelo IBGE ainda no século XIX. O autor foi jornalista, historiador, literato, fez pesquisas estatísticas da região de Uberaba, além de publicar mapas desta cidade e sua região (Triângulo Mineiro).

${ }^{5}$ Por imaginação aqui penso o mesmo que Deleuze \& Guatarri (2009)
} 
um nível microssociológico identidades locais, regionais e estaduais ${ }^{6}$. Historiadores, memorialistas, literatos/literatas, poetizas assim como estatísticos já faziam pesquisas reconhecidas pelo IBGE no próprio século XIX em Minas Gerais. Portanto, a criação de mapas, estatísticas e jornais apontados como centrais para a construção de sistemas culturais conforme pensa Anderson (2005, p. 39). Cada um destes elementos citados por Anderson (2005) tradicionalmente foi pensado sem ser relacionado a construção a identidades culturais locais, regionais e/ou estaduais, como podemos ver em por Schwarcz (1987; 1993; 1998).

Muitos trabalhos sobre a imprensa negra, por exemplo, fazem uma história da mesma como uma construção única e de resistência, da mesma forma como diversas autoras e autores fazem do abolicionismo. Portanto, estas experiências culturais são diluídas em histórias e realidades sociais gerais. A resistência via processos judiciais locais, por exemplo, é pensada como contribuições para um processo cultural mais amplo de luta por liberdade (nacional). Outrossim, outras pesquisas que tem formas culturais como objeto, como por exemplo a Congada, também diluem estas em uma identidade negra geral. A questão local aparece nestes casos com uma particularidade que justifica o estudo daquela tradição cultural específica.

A perspectiva pós-colonial realiza uma mudança central em relação a antropologia e sociologia clássica. Principalmente por se propor a pensar o sujeito construído por formas culturais específicas. Portando, desloca-se das formas culturais na direção da construção das subjetividades. Peles Negras, Mascaras Brancas de Franz Fanon (2020) é o maior exemplo desta virada. O tornar-se sujeito se configura como um ponto central de reflexão e pesquisa. A recepção de Franz Fanon (2020) possibilitou um novo olhar na direção dos processos de constituições de sujeitos. Tanto em relação ao presente, quanto relação ao passado. É justamente esta mudança de perspectiva que justifica retomar temas clássicos da sociologia e antropologia a fim de buscar novas interpretações.

Segundo Florestan Fernandes (2008b), mudança social foi o principal paradigma das ciências sociais no século XX até meados da década de 1970. O autor explica a mudança em função das transformações conjunturais mundiais. Estas alteraram a perspectiva sobre o que possa a ser interpretado como relações sociais em um território nacional. Para o autor, faz-se necessário apreendê-las na nova conjuntura como parte de relações globais; o que o autor compreende como nacional estaria começando a se estruturar em novas lógicas

\footnotetext{
${ }^{6}$ A forma como, estas diferentes identidades, se articulam é com certeza um problema sociológico e antropológico que carece ainda de reflexões maiores.
} 
supranacionais. Para Florestan Fernandes (2008b) esta mudança significava a perda da cidade como o principal campo empírico em que ocorria a transformação social. Não obstante, a cidade continuou tema, ou campo privilegiado, para a pesquisa antropológica, constituindo um campo de pesquisa específico - a antropologia urbana (HIRATA, 2010; DAMACENO, 2013).

Do ponto de vista da pesquisa sobre raça, a cidade também foi central. Uma vez que o tema era caro a sociologia da escola de Chicago, com quem Florestan Fernandes possuía diálogo crítico. O conceito de "ajustamento", central em Florestan Fernandes (1965a; 1965b; 2007; 2008a; 2008b; 2009), e que aparece também em Mannheim (1962; 1974; 1976), de quem falarei mais adiante em função do impacto que possui sobre Florestan Fernandes (DAMACENO, 2013, p. 83), só pode ser pensado por meio de uma dimensão territorial. Seria possível dizer que os mesmos territorializam-se $e^{7}$. Portanto, deste ponto de vista, o local, a cidade e o território estão presumidos dentro dos conceitos empíricos apreendidos tanto pela antropologia (em especial a urbana) como pela sociologia de Chicago.

Sobretudo, o próprio conceito de "atitudes raciais", caro a uma fração dos autores e autoras que se inspiram na sociologia de Chicago, seja para negar a existência de uma questão racial, como ocorria com Donald Pierson (DAMACENO, 2013, p. 87) ou para afirmar a existência, como com Virginia Bicudo (DAMACENO, 2013, p. 94), possui uma dimensão territorial presumida no conceito. Não obstante, como poderá ser visto pelo debate a seguir, havia uma outra perspectiva com a qual a sociologia de Florestan Fernandes debatia: o conceito de "área cultural" que pertence a Herskovitts (1941).

Todo este debate tem ainda marcas na forma de definir objetos, hoje, na sociologia e na antropologia. Contudo, a partir da década de 1970, os autores e autoras identificados com a corrente de pensamento que ficaria conhecida como "estudos culturais" e começam uma crítica a esta forma de pensar os campos de pesquisa, em função da sua ligação com a própria forma de imaginar os objetos do pensamento ocidental (SAID, 2007).

Os trabalhos de Edward Said (2007 [1978]) tiveram grande impacto nas ciências sociais como um todo. Principalmente por introduzir o problema de como conceitos, tais

\footnotetext{
${ }^{7}$ O conceito de territorialização é central nas obras de Deleuze e Guattari (1995, 1995b, 1996, 2009, 2010). O livro de Deleuze "Bergsonismo" da centralidade a este conceito, o relacionando com o de sujeito (DELEUZE, 1999). Contudo, o mesmo pode ser pensado a partir das obras de Paul Gilroy também, sobretudo em " $O$ Atlântico Negro" (GILROY, 2001) e em "Entre Campos (GILROY, 2007).
} 
como território, região, cidade são formas posicionadas de experiência. É possível interpretar que Raymond Williams, ao definir a cidade como uma realização da experiência humana, já havia aberto o caminho para estas novas formas de ver a cidade como uma forma de representação (WILLIAMS, 2011). O espaço passou a ser problematizado de uma nova forma pelas ciências humanas. É dentro deste quadro que o livro de Benedict Anderson é recebido. “Comunidades Imaginadas" (ANDERSON, 2009) retoma a questão de como os espaços são imaginados pelas populações.

Os autores e autoras que estão ligados ao estudo da diáspora africana incorporam as contribuições dos "estudos culturais", assim como também são impactados pelo trabalho de Benedict Anderson (2009). Em especial estes dois autores são centrais para compreender a obra de Paul Gilroy (1987; 1993; 2000; 2001; 2005; 2010). Contudo, a recepção destes autores e autoras no Brasil é recente. Poucas teses tem a diáspora como centro da sua discussão. Um pouco em função de um trabalho imenso que ainda precisa ser feito de olhar a sociologia e a antropologia do Brasil construída dentro dos parâmetros do nacional, para produzir um diálogo crítico com o pensamento sobre a diáspora. Neste sentido, este trabalho é uma primeira tentativa de aproximação.

Uma das tarefas que precisam ser realizadas é a releitura de objetos e textos clássicos da sociologia das relações raciais brasileiras, assim como de suas formulações originais para construir um diálogo crítico entre estas diferentes formas de pensar sociológico. Em especial faço aqui com uma parte da obra de Florestan Fernandes. Principalmente no tocante à Minas Gerais.

No caso de Minas Gerais há uma instância ainda não plenamente reconhecida e pouco estudada - a região - mas é central para a compreensão da dinâmica social do Estado. Outrossim, ao analisar autores clássicos como Florestan Fernandes (1965; 1965; 2007; 2008a; 2008; 2009), Gilberto Freyre (1973; 1981; 2004; 2009), Antonio Candido (1971) é possível depreender que o próprio Estado de Minas Gerais se constituía em um problema para as suas perspectivas. Embora haja imensas diferenças entre os autores citados, a generalização de uma cultura atrelada ao desenvolvimento das fases econômicas do estado em questão atravessa a todos os citados.

Cota (2013) recentemente trouxe uma nova forma de pensar esta dinâmica sociocultural das suas diversas regiões e das diferenças culturais neste estado. $\mathrm{O}$ autor buscou 
pelas raízes históricas das divisões regionais para compreender melhor como as mesmas se diferenciam em identidades culturais e políticas diferenciadas. $\mathrm{O}$ autor mostra a história destas divisões e centra-se nas características políticas do Triângulo Mineiro. Para o autor, a política distintiva da região era o abolicionismo. O autor se concentra no trabalho dos agentes sem entrar nas suas estratégias construídas. Os mesmos são analisados principalmente por seus trabalhos como jornalistas e na assembleia estadual.

O autor cria a possibilidade de ver como regionalmente (no caso de Minas Gerais e estadualmente em alguns casos) elementos considerados como característicos do abolicionismo são apresentados como um progresso local, frente a defesa do escravismo puro tanto nacional quanto no próprio estado e região. Como podemos ver pelo exemplo abaixo:

(...) A regência trina em 1831 promulgou a lei de 7 de novembro, e seus membros eram conservadores. Depois promulgou-se a do estadista Eusébio de Queiroz, depois a lei de Rio Branco, que proibiu separar-se a mãe escrava de seu filho menor de 12 annos; a lei do conselheiro José de Alencar que retirou da praça pública a arrematação de escravos, repugnante espetáculo á dignidade humana, porque rebaixava o homem á condição de bestas, que se vendem nas feiras públicas; finalmente a lei que autorizava os açoites, pena infamante abolida pelo ministério Cotegipe $^{8}$. (Jornal Sete de Setembro 25 de Maio de 1888)

Especificamente, Gustavo Cota (2013) procura deslindar a força da política abolicionista por meio da produção jornalística no período entre 1871 a 1888 pensando que o abolicionismo como o resultado de um diálogo que é regional. O editorial acima foi escrito para defender a perspectiva de um caminho progressivo da abolição, a partir do local, uma vez que a perspectiva senhorial de controle sobre as alforrias fora mantida, apesar da lei de 1831 (CHALHOUB, 2003; 2012), controle local também mantido (de forma mais precária) nas leis de $1871^{9}$ e $1885^{10}$.

Em específico o texto editorial se alinha a esta perspectiva, se coloca contra a proposta de uma abolição à revelia do Governo Imperial e estadual - proposta encampada

\footnotetext{
${ }^{8}$ Sete de Setembro. Diamantina, 25 de maio de 1888. SIA-APM.

${ }^{9}$ Apesar de no debate sobre a lei do ventre livre não ser retirada a prerrogativa de os/as próprias/próprios agentes requerer a sua alforria, fora impedido a intervenção de terceiros. No debate sobre a lei do sexagenário a questão era a tabela oficial para regular as alforrias.

${ }_{10}$ Joseli Nunes Mendonça (1995) trouxe uma perspectiva toda a disputa entorno dos outros elementos que seriam consolidadas na lei, principalmente em função do valor tabelado das alforrias, que diminuía mais o poder senhorial. Chalhoub (2012) posteriormente discute toda a disputa em relação a lei de registro civil (1852) e da própria lei de 1831 e as tentativas de revogar a lei.
} 
localmente ${ }^{11}$. A distinção entre o nacional e o local é essencial para compreendermos, portanto, o período em questão. O contraste se dá por localmente haver uma política cultural criada por abolicionistas desta região em específico, cujo limite era imposto nacionalmente através de leis abrangentes. Do ponto de vista dos direitos e da luta pela liberdade há vasta bibliografia que discute todas as limitações das leis citadas acima. Contudo, o que se observou menos é a possibilidade cultural criada por jornais regionais, no sentido que Benedict Anderson (2005) pensa. Há evidências para pensar como poderia existir uma possível identidade regional.

Considerando este período, podemos pensar com Raymond Williams (2014, p. 277) mais uma vez. Aproximando-nos dos seus estudos sobre a possibilidade de haver uma literatura regional. Há evidências de um amplo debate na imprensa mineira sobre problemas locais do abolicionismo. Há atas das câmaras de vereadores, livros, romances locais, jornais entre outras produções que são formas de difusão da língua. Os mesmos podem servir como fonte para pensar o estado da língua neste período, são igualmente registros de experiência humana e um recurso moral (WILLIAMS, 2014, p. 282). Do ponto de vista do autor, enquanto registro é possível pensá-los como elementos de uma determinada vida social, um problema político (WILLIAMS, 2014, p. 299).

Em sentido aproximado, pode-se pensar que a criação de uma cultura política local permitiria pressupor a existência de uma "comunidade cognoscível" (WILLIAMS, 2011, p. 278). O autor, ao discutir o que pensa como uma literatura regional, pondera que esta só pode ser pensada se esta forma de pensamento remeter a um problema, sendo este gerado por um modo de vida (WILLIAMS, 2014, p. 303). Pensando com o autor: há fontes para pensar que localmente havia a disputa política por um modo de vida. A questão colonial, principalmente o poder senhorial, é o tema do romance Helena, segundo Chalhoub (2003). A partir de autores que trabalham com processos judiciais movidos por escravizados/escravizadas durante o século XIX (MONSMA, 2016; MARQUES, 2011; CHALHOUB, 2011; 2012) demonstram como estes aconteciam nos tribunais locais inicialmente, e interpelavam o que Williams (2014) chamava de modo de vida senhorial.

\footnotetext{
${ }^{11}$ A análise de 36 jornais diferentes, de diferentes cidades de Minas Gerais, que estavam em debate constante desde pelo menos 1871, permite pensar que a narrativa da progressão dos direitos era um discurso, assim como o abolicionismo regional (SANTOS, 2019).
} 
Assim como outros autores e autoras que discutem sobre o tema, Gustavo Cota (2013) em sua tese: "Ave, Libertas: Abolicionismos e luta pela liberdade em Minas Gerais na última década da escravidão" (COTA, 2013), mesmo que sua pesquisa avance bastante em relação a esta forma de enquadramento dos objetos ${ }^{12}$, ainda o pensa relacionando as lutas por liberdade nacionais. Justamente por isso, o autor, apesar de conseguir pensar como o diálogo entre diferentes agentes, instituições e jornais constrói uma política diferencial para a região, não compreende esta diferenciação entre local, estadual e nacional. Por isto acaba por remeter todas as práticas que analisa à esta totalidade que projeta como instituição: "a escravidão".

Não obstante, quando se olha os números da região, pode-se ver uma força regional reforçando a visão de Gustavo Cota (2013) e como a política distintiva de representação da região tinha um peso considerável. Ouro preto possuiu 35 jornais na década de 1880, enquanto que Uberaba- MG possuía 20 (56 durante o século XIX) e Pitangui 11 (17 durante século XIX) $)^{13}$. Até 1888 a região possuiu 73 periódicos (COTA, 2013, p. 66). Comparando com os números que Lilia Schwarcz (1987, p. 57) apresenta, São Paulo Capital possuía 80 periódicos em 1880, para uma população muito maior. Contudo, como foi dito acima, os periódicos abolicionistas possuíam maior destaque. Havia uma ligação programática com o sul de Minas Gerais, em função de alguns abolicionistas, na assembleia estadual mineira, serem desta região (COTA, 2013, p. 172). Como o autor foca na construção do abolicionismo via agentes que encarnam esta ideologia, não trabalha a assembleia estadual como uma produtora de objetos discursivos para o abolicionismo (FOUCAULT, 2004).

Se por um lado o autor capta a política articulada estadualmente/transregionalmente, de forma articulada, entre estes agentes abolicionistas, Gustavo Cota (2013) não chega a pensá-los como uma forma, mesmo que rudimentar, de sociedade civil ${ }^{14}$. Outrossim, a sociedade da região é apenas um pano de fundo em seu texto. Apesar de trazer para a sua análise uma diferença política e de representações importante, que fazia parte de um conjunto mais amplo de discursos. Cota (2013) acaba por ter uma compreensão que individualiza a política distintiva regional, ao remetê-la ao plano das lutas por liberdade, e separa de forma

\footnotetext{
${ }^{12}$ Não fez parte do escopo do autor buscar compreender os discursos que permeavam os jornais que não eram abolicionistas. As trajetórias dos agentes estudados e dos jornais são vistas em si mesmas, como uma unidade temática discursiva (FOUCAULT, 2004).

${ }^{13}$ Esta cidade em específico é apontada como uma diferença cultural que tenderia a se homogeneizar à cultura do estado por Gilberto Freyre (2004; 2009).

${ }^{14}$ Ao debate atual sobre o abolicionismo, como o mais clássico, falta uma crítica sobre a possibilidade de haver eticidade como pensa Habermas. Outrossim, não há a qualificação dos abolicionistas como construindo uma esfera pública, nem uma sociedade civil.
} 
abstrata essa ideologia política da sociedade, por não a discutir do ponto vista da comunidade que lhe da vida. Para Gabriela Pereira Martins (2017), por exemplo, as sociedades abolicionistas inventadas, sobretudo, no século XIX, são melhor compreendidas se pensadas como atores coletivos, fruto também de um trabalho coletivo.

Por comparação, pode-se pensar que Gustavo Cota pensa o abolicionismo como um trabalho coletivo sem com isso admitir atores coletivos, embora a região possuísse diversas sociedades abolicionistas. A pergunta de Gabriela Pereira Martins (2017) é oportuna porque os trabalhos não admitem a existência de um sócius ${ }^{15}$ (GILROY, 2010, p. 11), fora o produzido pela sociedade escravocrata e seus agregados, não admite cultura fora desta mesma visão restrita de sociedade, como também não pressupõe política fora deste sócius.

Portanto, fora de uma generalização, de uma motivação psicológica (a busca pela liberdade), qualquer ação social é sempre pensada pelo signo da falta (DELEUZE, 1999). Esta perspectiva já existia na sociologia das relações raciais e permanece subentendida nesta forma de construir esses objetos contemporaneamente. Somente abstraindo a diferença entre os sujeitos e supondo que todos possuem a mesma motivação (a busca pelo direito de liberdade) é possível pensar uma unidade. Essa mesma generalização psicológica que subjaz as autoras e autores que compartilham do enunciado "os últimos anos da escravidão" é o que confere unidade no plano dos/das agentes para a análise.

Esta tendência também é compartilhada nos estudos sobre as estratégias criadas pelos/pelas agentes para buscar a liberdade. Por este motivo há a busca pelas "concepções de liberdade", embora haja a movimentação de muitos e muitas em busca de um "bem político" coletivo, a estas ações não é conferida nenhum poder significante, ou coletivo. Chalhoub (2012) possui uma passagem bem significativa e ilustrativa desta característica:

O foco da complexidade das apropriações sociais das categorias de "escravo" e "livre", mais uma porção de outras, tais como "liberto", "ingênuo", "africano livre", "preto livre", "boçal" e "ladino", "africano" e "criolo", mostrava-se estratégia segura, ou seguramente divertida, para a compreensão das logicas de mudança histórica e das experiências dos sujeitos naquela sociedade. $\mathrm{O}$ procedimento consistia em ler o documento muito devagar, sem tirar retrato de documento, tentando reconstruir na empiria as relações entre os ofícios, a troca de despachos à margem deles, a cronologia correta dos eventos referidos, a relação entre conteúdos e as formas de texto, de maneira a vislumbrar e subverter categorias sociais amplamente compartilhadas e mui contraditoriamente apropriadas pelos sujeitos históricos (CHALHOUB, 2012, p. 29).

${ }^{15} \mathrm{O}$ conceito de sócius em Paul Gilroy (2010) parece ter o mesmo significado que em Deleuze \& Guatarri (2010): Um plano de relações onde é possível construir formas de descentramento. 
Pela passagem acima é possível entender como estratégias significantes regionais escapam a esta perspectiva. Toda e qualquer diferença é submetida a um sujeito coletivo externo e superior. As classificações citadas são uma expressão deste/desta agente ${ }^{16}$, desta forma não possuem um significado em si, nem representam um trabalho dos sujeitos sobre si mesmos, como pensa Foucault (2016, p. 30). Desta forma são expressões culturais, mas não constituem atos simbólicos, nem são parte de uma ideologia. Assim como a ideologia é externa a estes pequenos atos [small acts] na visão de Paul Gilroy (1993), e aos sujeitos coletivos que encarnam essas classificações, como nos diz autor.

Isso é importante para entender que há toda uma bibliografia que trabalha com a mesma perspectiva. Justamente por remeter a este sujeito coletivo esta bibliografia concebe o abolicionismo apenas no singular, como uma ideologia. E as diferenças que ocorrem em diversos locais acabam por serem enquadradas como "contradições". Chalhoub $(2011 ; 2012)$ não considera como luta a recognição que um sujeito faz, ainda que fosse passar de uma categoria racializada a outra, para o autor isto não constitui como memória de uma luta social (GILROY, 2010, p. 03). Muitas vezes o local aparece como uma destas contradições. Neste sentido, as ações locais são também remetidas a uma ideologia geral. A forma como determinados fatos históricos e construções culturais se ligava à cultura política local não entrava como instância nas pesquisas. A relação entre local e nacional, desta forma, não foi percebida como uma via dupla de estruturação. O local é uma instância de realização de processos mais amplos e complexos.

Mesmo considerando que durante o século XIX houve uma progressiva luta social que levou ao crescimento dos direitos, isso não significa que a "cidadania" alcançada em 1888 não fosse racializada (GILROY, 2010, p. 71), uma vez que esta torna a diferença fenóptica em um fenômeno pré-político. Não foi apenas o abolicionismo que tornou o novo regime republicano nascente em racializado, isto é, uma construção coletiva da qual fazem parte os abolicionistas. O enunciado "nos últimos anos da escravidão" não se constitui em uma contranarrativa dos direitos contra a ordem política racializada. Uma vez que trabalham dentro deste ponto de vista, não percebem as políticas racializadas que sustentam uma concepção de Estado

\footnotetext{
${ }^{16}$ Hall (1980, p. 307) considera que há duas posições dominantes quanto a etnia: a) os que consideram como expressão cultural, b) como uma contradição dentro de formações econômicas.
} 
Republicano nascente como cego as demandas de reconhecimento das populações descendentes de africanas e africanos.

Ianni (1962), em texto hoje clássico para a sociologia das relações raciais, ao pensar como passagem a transformação do negro em cidadão, pode ser visto como um exemplo da discussão acima. Uma vez que o abolicionismo é caracterizado como uma ideologia nova préordem social. Desta forma, retoma a tese de Florestan Fernandes (1965a, 1965b) em "A Integração do Negro na Sociedade de Classes". Neste sentido, o não-ser preexiste ao ser (como a desordem que preexiste a ordem). Como o objetivo dos autores é compreender a "ordem social competitiva" é necessário supor que há neste não-ser o "germe" do ser. Deste ponto de vista os/as escravizados/escravizadas são pensados/pensadas como uma negação. Esta arquitetura pretendeu separar a República do império, separando a ordem racial (temporalmente delimitada no império) da nova ordem capitalista (República). Por conseguinte, os autores, ao pensar o/a negro/negra como negação os/as mesmos/mesmas só podem ser pensados pelo signo da falta, dentro da ordem social nova presumida pelos autores. Portanto, realidades diferentes são diluídas em uma ser geral: a classe (DELEUZE, 1999, p. 12).

No sentido que Gabriela Pereira Martins (2017) pensa, haveria uma sociedade politicamente ativa em várias regiões de Minas Gerais, como mostra o trabalho de Gustavo Cota (2013). A autora e autor acima não veem a política e cultura como permeáveis, nem como expressões da sociedade. Autora e autor acima citados pensam do ponto de vista da produção, não pensam a sociedade, a política, cultura como produto e produtores (DELEUZE \& GUATARRI, 2010). Quando Mario Augusto Medeiros (2013) analisa a trajetória de Maria Carolina de Jesus ${ }^{17}$ apreende como um modo de vida fora produzido e foi a base da produção da subjetividade da autora. O autor não separa política e cultura para construir a sua análise, Lilia Schwarcz (2017) faz o mesmo em relação a Lima Barreto. Uma nova produção sociológica tem conseguido apreender o abolicionismo como um conjunto de ideologias em vez de uma, no singular, deixando de ver como totalmente impermeável a sociedade.

Ao remeter as práticas significantes, formas de subjetivações, Chalhoub (2012), como faz na passagem acima, as dimensões complexas da construção de formas de subjetividade são reduzidas a expressão de um sujeito coletivo. O autor neste sentido está dentro de um

${ }^{17}$ Maria Carolina de Jesus nasceu na região ora estudada. 
conjunto maior de autores e autoras que não percebe estas expressões como recognição [recognicion] e/ou demandas de reconhecimento (GILROY, 2010).

Inverter a perspectiva, pensar do ponto de vista local permite reconstruir rastros, passos ambivalentes que articulam espaços de construção de identidades culturais, espaços para produção de formas de sujeitos, outras formas de políticas. A construção de um espaço, onde os agentes produzem formas de recognição [recognicion] - descentramento - são influenciadas por um contexto político específico, e também pela história de cada parte acima descrita. Para Paul Gilroy (2005, p. 29) o caminho passa por retomar as questões locais e conjunturais, para compreender suas características, mas também para compreender como um conjunto de pessoas, localizadas em um espaço, resistem historicamente a tentativas de totalização da sua experiência inventando identificações.

Segundo o autor a questão é compreender a raça enquanto ordem política que endurece caráter étnicos dos grupos na sociedade (GILROY, 2005, p. 31). As razões como isto ocorre no Brasil são muito distintas do que ocorre no Reino Unido, de onde o autor escreve. Creio que é preciso pensar a questão local de forma a conseguir compreender como se articulam os diferentes níveis, buscando compreender cada uns dos agentes (coletivos ou individuais) participam deste processo. $\mathrm{O}$ que para o autor começa pelo levantamento de todas as ontologias históricas que se sobrepõem as localidades (GILROY, 2005, p. 32).

Para o autor é necessário problematizar o imaginário construído ao longo do período colonial, assim como as representações e identificações. Uma diferença central do novo momento pós-colonial é o estabelecimento da intermistura e intercultura, demarcando como muito mais fluidas e complexas as relações do que o binarismo baseado na cor (GILROY, 2005, p. 42). Desta forma é possível pensar como as condições históricas especificas constroem as identidades raciais, produzindo tanto raça quanto etnia como totalidades (GILROY, 2005, p. 43). Neste sentido seria possível compreender o dano cultural imposto as populações descendentes de africanas e africanos.

O período histórico que o autor toma como referência para a sua análise do póscolonial seria o imediatamente após o fim do império Britânico como estava configurado no século XIX e permaneceu até o fim da segunda guerra mundial. A discussão sobre o póscolonial no autor se dá dentro das condições que a Inglaterra se coloca em relação aos padrões culturais criados pelos milhares de imigrantes das ex-colônias que chegam ao Reino Unido. 
Esta dimensão parece marcar a vida do autor, uma vez que ele próprio é filho de uma imigrante de uma ex-colônia. Por isto o livro que ora comento se chama no Reino Unido “After Impire” e nos Estados Unidos "Poscolonial Melancholia". Creio que a diferença dos nomes já reflete a forma como ocorreu o debate em cada um destes países, mas também a forma e lugar que cada país tem em sua teoria. Principalmente no que toca o papel que cada um desempenha na diáspora.

Em primeiro lugar o nome "After Impire” parece ter duplo sentido - este é o nome no Reino Unido. Diretamente remete ao período pós-guerra da Inglaterra/Reino Unido, mas também se relaciona com o período onde os Estados Unidos se estabelecem como um "império". Os dois fatos afetam os padrões da intercultura e intermistura no Reino Unido. No primeiro caso, em função dos padrões culturais diaspóricos vernáculos do Reino Unido em segundo porque a música afro-americana estabelece um padrão cultural globalizante. Fato que é analisado em dois outros livros, no caso "Entre Campos: Nações, Culturas e o Fascínio da Raça" (GILROY, 2007) e em "Darker than Blue: On the Moral economies of Black Atlantic Culture" (GILROY, 2010). A questão do consumo abordado nos livros seria a razão pela desagregação das comunidades interpretativas inventadas durante o período colonial.

A versão brasileira de "Entre Campos: Nações, Culturas e o Fascínio da Raça” possui o mesmo nome da versão britânica. Não obstante, o livro na versão americana se chama "Against Race: imagining political culture beyond the color line". Uma vez que discute como a transformação das relações econômicas, criadas pelas novas condições de exploração, afeta as possibilidades de criação de intersubjetividade. Principalmente por a música, enquanto uma comunidade interpretativa, ter perdido esta condição. Principalmente em função do "fascínio da raça" que surge por meio da ascensão da música "afro-americana". "Against Race" dialoga com a questão nos Estados Unidos mais do que a referência a ideia de terceiro espaço do nome do livro no Reino Unido (Entre Campos). Em todo caso haveria uma oposição. Nos Estados Unidos há a produção de uma perspectiva despolitizada e um conceito de raça que se fortalece por meio do consumo mundial, oposta às comunidades interpretativas produzidas pelas interculturas no Reino Unido, em especial na Inglaterra.

No caso, parece aqui haver outro duplo sentido. Pois o contexto inglês apontaria para uma intercultura diaspórica diferenciada, por isto pode ser pensado como um campo. A história dos Estados Unidos se parece mais com a do Brasil, em função da escravidão estar 
relacionada a questão colonial local. O contexto norte-americano apontaria para outro padrão de intercultura - que pessoalmente imagino ser diferente do Brasil, mas com certeza é diferente do Reino Unido. O que poderia ser pensado como um novo campo.

Para Paul Gilroy $(2005 ; 2007 ; 2010)$ a perspectiva da desracialização estaria entre esses dois campos - Estados Unidos e Reino Unido. Na medida que a intercultura criada pelo contexto diaspórico britânico se integra à globalização inventada pelo campo dos Estados Unidos. Seria a diferença entre uma batalha por direitos, no caso do Reino Unido, oposta a batalha por objetos. No caso em função do consumo ter como característica ser despolitizante dos Estados Unidos (GILROY, 2010, p. 33).

De certa forma o problema na forma como a diáspora é colocada por Stuart Hall, Avtar Brah (2011) e Hommi Bhabha (2013) tem bastante semelhanças neste sentido com Paul Gilroy $(1987 ; 1993 ; 2000 ; 2001 ; 2005 ; 2007 ; 2010)$. Pois os autores e a autora discutem a partir de universos culturais específicos e que possuem uma história semelhante. A circulação de cultura por meio da língua inglesa comum a estes universos facilita a transmissão de códigos. Creio que uma dificuldade que esta perspectiva enfrenta é justamente como integrar a esta base de pensamento o universo criado em outras línguas, sobretudo em francês e português. Outrossim, dentro destes universos, há a questão de como as diferenças se estabelecem. No caso, como as populações descendentes de africanos e africanas construíram identificações criando formas de descentramentos, inventando cultura e atuando como minoria, no sentido que Deleuze e Guattarri (1977) pensam este conceito ${ }^{18}$.

Para Paul Gilroy (2005) um dos pontos unificadores de contextos da diáspora é a condição comum dos contextos. Em todos as invenções, as formas de descobertas do self, se fazem frente ao que o autor chama de "espaço de morte" (GILROY, 2005, p. 43). O laboratório de invenção do self está oposto ao exercício governamental da codificação do conhecimento e da raça (GILROY, 2005, p. 43). Em diversos momentos o autor tentou conceituar a forma como nasce esta diferença. Em Small Acts (GILROY, 1993, p. 105) o autor pensava a "tradição oposicionista" como oposta, completamente, a outras totalidades culturais. Diferente da proposta em seu último livro onde estas "tradições oposicionistas" são vistas como interculturais por excelência (GILROY, 2010). O autor agora pensa esta tradição intercultural como oposta a formas que se fecham à esta interculturalidade.

\footnotetext{
${ }^{18}$ Bhabha (2013) utiliza o conceito de minoria de forma muito próxima destes dois autores.
} 
Voltando, o que o autor pensa como pós-colonial se relaciona com as demandas de reconhecimento construídas no período anterior à segunda guerra- durante o período colonial - pois a intercultura é dupla. Primeiro porque parte dos imigrantes são agentes descendentes de africanos e africanas nas ex-colônias, o que já coloca uma questão diaspórica. Em segundo lugar por ao chegar às antigas metrópoles estes imigrantes relacionam as nacionalidades de origem, trazendo uma cultura que no país de origem era diaspórica, como acabei de dizer, com a nacionalidade da metrópole. Onde há outras culturas diaspóricas vindas de outras partes do antigo império. Esta questão é enfrentada pelo autor em "There Ain't no black in the union jack" (GILROY, 1987), texto mais antigo onde autor faz suas primeiras incursões no tema ${ }^{19}$.

Pensando a região do Triângulo Mineiro, as culturas de origem, das africanas e africanos e seus descendentes se tornam uma forma de classificação nos documentos oficiais produzidos pelas instituições, conforme demonstra Chalhoub $(2011 ; 2012)$. Ao contrário do contexto Britânico estes/estas agentes não se encontram com uma cultura (ou várias culturas) sedimentadas com uma literatura consolidada que sedimentou subjetividades, mas sim como uma determinada cultura que está em processo de produzir a sua própria narrativa. Esta, por sua vez, apaga a existência da diferença racial e mesmo as migrações internas do Brasil de descendentes de africanos e africanas livres.

Florestan Fernandes (1965a; 1965b) considerou a migração para São Paulo e a que partia para o interior, saindo, portanto, da capital deste estado. Apesar de Florestan Fernandes citar estes fluxos, não os considera para as suas formulações. Pensar neste contexto a intermistura significa considerar as relações estabelecidas entre as subjetividades produzidas pelos diferentes fluxos migratórios de africanos e africanas (livres e não livres), as representações construídas sobre estes/estas agentes, assim como as culturas diaspóricas criadas neste espaço. Sendo que estas não são referidas nas narrativas de origem inventadas durante este mesmo período do Segundo Reinado.

O problema do diálogo com a produção que utiliza o conceito de diáspora passa justamente por conseguir ultrapassar um certo isolamento na qual as culturas inventadas pelos/pelas descendentes de africanos e africanas no interior do Brasil se encontram, como foi

\footnotetext{
${ }^{19}$ Neste sentido, a perspectiva de Stuart Hall está mais próxima de Paul Gilroy do que Brah (2011) e Bhabha (2013). Em relação a este autor e autora, há uma dimensão mais estrutural em suas visões do que cultural, pois o terceiro espaço prescinde de uma ligação cultural. É uma possibilidade para os agentes em culturas diaspóricas.
} 
discutido acima. Tanto em termos políticos, culturais, sociais quanto em termos teóricos. Primeiro por serem apreendidos isoladamente, isolando a cultura da política, a cultura e a política da sociedade. A própria discussão teórica está isolada da que está sendo feita internacionalmente, com exceção de Azevedo que reposiciona o abolicionismo do Brasil dentro do contexto internacional. O que aparece também em Mario Augusto Medeiros da Silva (2013), Gustavo Cota (2013), Gabriela Pereira Martins (2017). Até aqui discuti o isolamento criado pela forma de enquadrar os objetos, é preciso discutir ainda o isolamento em que a teoria se encontra em função da contribuição de alguns autores, sobretudo Florestan Fernandes.

A questão é, portanto, recuperar as histórias de luta de todos os agentes descendentes de africanas e africanos. Para tanto, é preciso recuperar as demandas de recognição [recognicion] e por reconhecimento. O que significa fazer uma história, tanto quanto possível, destas demandas de reconhecimento e recognição [recognicion] (GILROY, 2010). É preciso buscar as tradições locais (culturais e políticas) do espaço ao qual se pretende pensar (GILROY, 2005, p. 30). Contudo, estas tradições político-culturais estão sob tentativas de totalização da sua experiência que se acumulam ao longo do tempo. Do ponto de vista do presente: 129 anos de totalizações por meio de narrativas locais, regionais e nacionais. É preciso buscar situar novamente dentro de um contexto que é transnacional e translocal, e este tem sido o maior problema para a teoria.

Para Paul Gilroy (2010, p. 05) é preciso recuperar a história dos espaços de liberdade, pressupondo que durante o período da escravidão houve invenção de culturas vernáculas. Estas culturas são a forma como os/as agentes buscam a ressignificação do conceito de humano. Por conseguinte, a questão é superar a ideia de uma ideologia social, como em Chalhoub $(2003 ; 2011 ; 2012)$. É preciso compreender a forma como se dá a subordinação à qual as populações estão sujeitas (GILROY, 2005, p. 93), porque a alienação à qual os/as agentes estão sujeitos/sujeitas precisam ser compreendidas a partir dos termos culturais, que também são vernáculos. É preciso compreender este problema cultural para pensar o que Fanon (2008) chamou de dialética do olhar.

De certa forma esta perspectiva tem sido seguida por diversos autores e autoras. Em especial Célia Maria Marinho de Azevedo quando busca uma perspectiva diferente da que já 
havia feito antes (AZEVEDO, 1987), assim como de Schwarcz (1987; 1993; 2017), Schwarcz \& Starling (2015) Correa (1983), Bastos (2006).

Outrossim, é preciso repensar como inserir a ideia de interculturalidade para pensar as culturas diaspóricas vernáculas que existem na região do Triângulo Mineiro. Pois esta proposta significa quebrar com a série de pressupostos construídos pela teoria social no Brasil. É preciso pensar como Florestan Fernandes (1965; 1965; 2007; 2008a; 2008; 2009) impacta o campo, pela forma como enquadra seus objetos.

Outrossim, é preciso buscar os espaços de liberdade construídos pelos/pelas agentes, propõe o autor. São nestes espaços onde são inventadas tecnologias dos sujeitos ${ }^{20}$. Pensados como uma tradição, estes se construíram ao lado da ordem política. As lutas sociais movidas se opõem à territorialização da raça. Por este motivo o autor define o diaspórico como sendo cognição e recognição (GILROY, 2010, p. 35). Esta busca por estes espaços é feita dentro dos próprios arquivos coloniais. Os espaços de invenção/recognição existem dentro da própria dinâmica interna do colonial (GILROY, 2010, p. 77).

Por espaços o autor entende uma forma de política cultural, ainda que local, onde os/as agentes ensinam a sua forma de liberdade. Ou seja: as formas de recognição e ressignificação são formas de espaço (GILROY, 2005, p. 40) ${ }^{21}$. Por meio de quaisquer objetos culturais que possam ser ressignificados, ou criar uma forma para a aceitação de uma subjetividade. Formas de criar vínculos, uma forma de verdade que obriga uma pessoa em relação a outras (FOUCAULT, 2016, p.15).

O segundo passo nesta linha de desenvolvimento de argumentos é buscar compreender os efeitos da aceitação dessas obrigações na experiência que os sujeitos têm de si. Não que seja possível adentrar à experiência dos/das agentes, mas é possível ver como um espaço de modificação dos seres (FOUCAULT, 2016, p. 30). Portanto, estas operações que são de significação, conceituação, são em si um espaço de diferença. Conceitos são reinscritos, ressignificados, deslocados e por isto singularizados. A produção de conceitos é feita sobre objetos culturais que necessariamente tem origens diferentes. Fazem partes de outros sistemas

\footnotetext{
${ }^{20}$ Aparentemente o autor usa esse conceito no mesmo sentido que Foucault (2016), uma vez que o autor está ligando a invenção à criação de formas de alteração dos sujeitos, feitas por si mesmos.

21 Implicitamente o autor coloca o corpo como um espaço que também é ressignificado, passa por uma recognição. De novo em sentido muito próximo ao que Foucault (2013) em 'O corpo utópico, as heterotopias". Neste livro o autor considera que um contraespaço é uma invenção (FOUCAULT, 2013, p. 20), tal qual uma contranarrativa. O que casa perfeitamente com a perspectiva sustentada por Gilroy (2005; 2010). Como espaços outros que constroem as suas próprias regras.
} 
até serem deslocadas. As relações produzidas entre estes conceitos deslocados formam uma territorialização.

Retomar as tradições locais, as formas locais, os conceitos, narrativas, tem como função entender como a intercultura é produzida por um espaço qualitativo que desloca significados. Neste sentido, há um processo de troca. A produção deste espaço de cultura, de liberdade se faz mudando os conceitos para si e para os sistemas nos quais estes conceitos faziam parte. As regras que agora são produzidas dentro deste contexto, porque a produção da subjetividade como sendo possível de ser aceita, por produzir vínculos entre agentes. Isto implica em ver aquelas classificações que Chalhoub (2012, p. 29) pensou como apropriações de um sujeito histórico como formas de recognição [recognicion] (GILROY, 2010).

A proposta pós-colonial fornece a oportunidade de mudar a forma de construir as interpretações. Há elementos já apontados por outros autores que apareciam de forma marginal, em função de um entendimento baseado principalmente em Florestan Fernandes (1965; 1965; 2007; 2008a; 2008; 2009), que levaram a pensar diferenças como contradições (como indicado acima) e questões culturais como totalidades em si (que serão analisadas a frente). Brandão (1977), analisando uma região da qual o Triângulo Mineiro já fez parte (como poderá ser visto adiante) e politicamente sujeita, percebeu que uma diferença cultural surgia de uma localidade que nasceu de uma situação de liberdade ${ }^{22}$.

O trabalho de Alencastro (2000) trouxe a possibilidade de repensar alguns pilares. O autor apresenta o envolvimento dos brasileiros nos empreendimentos coloniais portugueses na África. O que desmistifica uma separação completa do segundo reinado em relação aos empreendimentos coloniais portugueses. Assim como o autor desmistifica a falta de contato com a cultura portuguesa de, pelo menos, parte dos africanos e africanas traficados para o Brasil (ALEMCASTRO, 2000, p. 290).

Por conseguinte, há uma bibliografia que isola o abolicionismo do contexto internacional, tem dificuldade para diferenças locais e regionais. Ao lado de outra bibliografia que remete as ações dos/das agentes a um sujeito coletivo, submete toda diferença a uma expressão do sujeito coletivo. Em ambas as visões o local não é uma instância de análise, uma vez que os agentes, as ações, as representações ou ideologias são tomadas em termos nacionais.

\footnotetext{
${ }^{22}$ Em uma perspectiva menor, a região foi revisitada recentemente por Paulo Sérgio Moreira da Silva (2012).
} 
Outrossim, a visão pós-colonial constrói uma perspectiva que permite pensar o local. Muito embora a teoria tenha pressupostos que precisam ser pensados, posto que foram construídos em função de outras espacialidades, no caso Estados Unidos e Reino Unido/Inglaterra. Apreendendo apenas a teoria em Paul Gilroy é possível aplicar a um contexto no Brasil. Não obstante, esta perspectiva possibilita deslindar as narrativas que se constroem sobre a experiência dos/das agentes descendentes de africanas e africanos. Se for possível provar a existência de espaços de liberdade em meio as narrativas que buscam totalizar a experiências, então propriamente esta tese estará provando que este local é parte do rizoma Atlântico Negro. É preciso descentrar as narrativas para buscar estes espaços de liberdade.

Considerando este objetivo, que é apreender a partir do local as histórias locais e as conjunturas de construção das subjetividades é preciso buscar a forma de fazer isso. Durante a pesquisa de doutorado, realizada pelo autor deste texto, as câmaras municipais se provaram uma instância articuladora de objetos culturais (FOUCAULT, 2004) e atravessadas por diversos discursos.

Voltando a parte anterior, há uma parcela da população sem que exista reconhecimento simbólico e político das mesmas hoje. Ao mesmo tempo, deslocando-se para o passado a perspectiva se inverte: historiadores, memorialistas, poetas e poetisas que viveram durante o século XIX reconhecem a existência de populações descendentes de africanas e africanos. Ao mesmo tempo que são a fonte para a criação das narrativas totalizadoras da experiência, que vão ser adotadas pelo poder público a partir do século XX. Tratarei mais à frente do problema das pesquisas que abstém da história, caindo assim em um tipo de culturalismo.

Por conseguinte, como já dito cima, havia duas opções a seguir. A primeira seria pensar sobre o atual momento em que estas populações se encontram. O que significava buscar uma forma de apreender estas comunidades sob as narrativas que dividem as populações em áreas diferentes e pretendem totalizar as suas experiências. Pensando com Paul Gilroy (2010), é preciso dimensionar as consequências do período imperial sobre as fases imediatamente posteriores.

A discussão sobre o Segundo Império precisa ser matizada pelas necessidades de compreender qual era a política cultural deste regime político, mas sobretudo, compreender 
melhor como o local, o estadual e o nacional se articulavam neste período. Pressuponho, pelos dados que possuo, que a dinâmica regional é essencial para compreender esta lacuna que existe em diversos autores e autoras no que toca à falta de uma forma apropriada para apreender fenômenos sociais em um plano local.

Por conseguinte, a forma como Paul Gilroy (2001; 2005; 2010) compreende o colonial, está muito ligada às espacialidades que informam a sua teoria. Desta forma o colonial não pode ser comparado mecanicamente ao imperial no Brasil. Foge ao escopo, aqui, conseguir apreender o segundo império como um todo para fazer esta comparação de forma mais aprofundada. Contudo, espero ter conseguido demonstrar os problemas das teorias que dão como um dado de realidade a unidade deste período, para no espaço criado por estas lacunas pelo menos tentar discutir uma destas: construir uma forma de apreender uma dinâmica de territorialização a partir do local.

Apesar do problema apontado acima no que toca a forma de aplicar o pensamento de Paul Gilroy $(2001 ; 2005 ; 2010)$, a busca aqui por compreender o seu método de análise, se constituiu em um esforço para não partir de uma concepção que toma como um pressuposto que havia no Brasil uma unidade da língua que apagou as diferenças entre os agentes, que toma o étnico como uma etapa superada pela integração à sociedade brasileira pelas populações de origem africana. Assim como deduzem a diferença cultural persistente, não só nesta região, como uma forma de prova de uma etnicidade africana. Do ponto de vista do autor, a moderna diferença racial se apropria do corpo como um fundamento da diferença racial, em virtude da origem (GILROY, 2005, P. 10).

O livro acima citado fora escrito com um diálogo crítico com os autores e autoras que discutem raça do ponto de vista da biopolítica. Por isto certos debates aparecem neste texto. Por isto que Paul Gilroy discute o conceito de melancolia diretamente com Hannah Arendt ${ }^{23}$, Agamben, Foucault e Adorno, em especial em relação ao último, em relação ao seu conceito de modernidade. No que toca a este autor, há uma dimensão da sua teoria que problematiza a dimensão da perda, da falta como um elemento central da modernidade - a melancolia seria o sentimento de perda daquilo que nunca se teve. Contudo, ainda que estas coisas não tenham

\footnotetext{
${ }^{23}$ Em "Origens do Totalitarismo: antissemitismo, imperialismo, totalitarismo", Hannah Arendt (2012) esvazia qualquer agencia possível do conceito e raça. Essa particularidade é importante, falta ainda hoje uma comparação com a produção feita no Brasil na mesma época do lançamento deste livro.
} 
sido realmente perdidas, há o sofrimento por esta perda. Adorno explica isto pelo mito de origem do ocidente.

Nesta forma de conceber a modernidade, a proposta dialética de pensamento impõe a superação das dicotomias modernas entre pensamento e ser, sujeito que conceitua e objeto conceituado, forma e conteúdo, conceito e intuição. Pois esta forma de pensar teria rompido com a projeção do eu no mundo. A dialética visa superar pela experiência crítica dos objetos o descompasso entre experiência e representação. Esta contradição tem caráter produtivo. Portanto, o movimento de negação dos conteúdos da experiência constrói um novo saber, que integra essa experiência a um novo conceito, forma de saber acessível à consciência do sujeito, o que implica o achatamento da subjetividade, retirando do múltiplo a unidade (ADORNO, 1999; 2013; SAFATLE, 2013) ${ }^{24}$.

A concepção de contramodernidade (GILROY, 2001) que propõe vai na direção oposta. A crítica radical de como o período colonial foi, sobretudo, um espaço de morte dinâmico, que impunha uma condição de unidade, como forma de violência, visa estabelecer que a melancolia se instaura no pós-colonial em função das demandas políticas, culturais, simbólicas não reconhecidas (GILROY, 2005, p. 43). O Colonial cria o moderno a partir do dano cultural. Por este motivo o sentimento de perda e sofrimento é pelos direitos de reconhecimento político, cultural e existência simbólica. A raça é constituída por este dano, por este motivo o autor a conceitua como sendo "ilha melancólica da raça" (GILROY, 2005, p. 102).

Os elementos de diferença cultural, que surgem no século XIX, tem o mesmo enquadramento teórico. De modo que o desenvolvimento da nacionalidade é pressuposto, mas não explicitado. A condição nacional é atribuída de forma universal por meio de uma construção unilinear da nacionalidade. Do ponto de vista de Foucault (2004, p. 14), essa construção por incorporação das diferenças via experiências visa ser sedimento para uma consciência. Desta forma toda uma fase histórica (segundo reinado no caso) pode ser vista sem rupturas - principalmente para Florestan Fernandes. O Segundo Reinado se torna uma

\footnotetext{
${ }^{24}$ Em especial Hegel é retomado por Charles Taylor em diversos escritos seus. E fundamenta uma crítica da modernidade para pensar a autenticidade cultural. Aganben é criticado diretamente por Paul Gilroy (2010, p. 85) por sua concepção ignorar a lei racializada e não considerar importante o discurso racial para a sua teoria (GILROY, 2005, p. 83). Em relação a Hannah Arendt (2012) à considera essencial para uma crítica ao estado de exceção e da máquina do genocídio (GILROY, 2010, p. 82) e por compreender a necessidade de expansão dos direitos, por meio de uma crítica a ideia hegemônica de direitos humanos (GILROY, 2010, p. 85).
} 
tese a ser superada, assim como a sua "ideologia" (o abolicionismo). Creio que a forma de construir do autor sacrifica a diferença cultural em detrimento de uma unidade.

Portanto, para ir no sentido oposto, é preciso buscar as formas de recognição realizadas pelos/pelas agentes. Assim como dos materiais pelos quais os agentes realizam estes processos simbólicos de deslocamento. Particularmente, a questão é construir uma forma de pensar que seja capaz de não sacrificar a diferença cultural.

Outrossim, é possível fazer um paralelo com a crítica ao período do segundo reinado para compreender o dano cultural ao qual os/as descendentes de africanas e africanos estavam sujeitos. Com o objetivo de compreender qual eram as demandas de reconhecimento que possuíam, e qual eram as formas de recognição que empregavam. Em minha tese de doutorado, começo por resgatar o papel das câmaras, jornais, romances, poesias publicadas em jornais da época, como um ponto nodal na unificação de realidades (ANDERSON, 2009) para poder conseguir estabelecer de que maneira estes documentos se tornam a forma pela qual os/as agentes construíam a sua territorialidade. Um modo de vida, como discutimos acima a partir de Raymond Williams (2014).

\section{Referências}

ADORNO, T, W. Textos escolhidos. São Paulo: Nova Cultural, 1999. Três Estudos Sobre Hegel. São Paulo: Editora UNESP, 2013.

ARENDT, H. Origens do Totalitarismo: Antissemitismo, Imperialismo, Totalitarismo. São Paulo: Companhia de bolso, 2012.

ALENCRASTRO, L, F. O Tratado dos Viventes: Formação do Brasil no Atlântico Sul Séculos XVI e XVII. São Paulo: Companhia das Letras, 2000.

APPIAH, K, A. Na casa de Meu Pai: África na Filosofia da Cultura. Rio de Janeiro: Contraponto, 1997.

ANDERSON, B. Comunidades Imaginadas. Companhia das Letras. São Paulo, 2009.

ARCANJO, F. O Rufar das caixas: sincretismo e identidade negra em Catalão através das Congadas. Programa de Pós-Graduação em Ciências da Religião. Pontifícia Universidade Católica de Goiás. Goiânia. 2003. 
ÁVILA, C, C, O. Itinerâncias e inter-heranças: do ritual do congado da zona da mata mineira ao processo de criação da performance em dança contemporânea. Instituto de Artes Programa de Pós-Graduação em Artes- Unicamp, Campinas, 2015.

AZEVEDO, C, M, M. Onda Negra Medo Branco: O Negro no Imaginário das Elites no Século XIX. P Rio de Janeiro: Paz e Terra, 1987.

BASTIDE, R. As Américas Negras. São Paulo: EDUSP, 1974.

BAStOS, E, R. As Criaturas de Prometeu: Gilberto Freyre e a Formação da Sociedade Brasileira. São Paulo: Editora Global, 2006.

BERGARD, L. W. Escravidão e História econômica: Demografia de Minas Gerais 17201888. Bauru: EDUSC, 2004.

BHABHA, H. Nación y narración: entre la ilusion de uma identidade y las diferencias culturales. Buenos Aires: Siglo Veintiuno Editores, 2010.

O Local da Cultura. Belo Horizonte: Editora da UFMG, 2013.

BILHARINO, GUIDO. Uberaba: dois séculos de história (dos Antecedentes a 1929). Arquivo Público de Uberaba. 2007.

BRASILEIRO, J. O ressoar dos tambores do congado - entre a tradição e a contemporaneidade: cotidiano memórias disputas (1955-2011). Programa de PósGraduação em História. Universidade Federal de Uberlândia. 2012.

BORGES, C, M. Escravos e Libertos nas irmandades do rosário. Devoção e solidariedade em Minas Gerais - século XVIII. Juiz de Fora: Editora UFRJ. 2005.

BRAH, A. Cartografías de la Diaspora: Identidades em cueston. Traficantes de sueños, 2011.

. "Diferença, Diversidade, Diferenciação". S/D.

BRAH, A. \& COOMBES, A, E. Hybridity and its Discontents: Politics, Science, culture. London; New York: Routledge: Taylor \& Francis Group, 2000.

BORGES, C, M. Escavos e Libertos nas Irmandades do Rosário. Devoção e Solidariedade em Minas Gerais. Século XVIII. Juiz de Fora: Editora UFRJ. 2005.

CAPONEIRO, M, C. Festejando São Benedito: A congada em ilha Bela, recurso cultural brasileiro. Pós-Graduação em estática e artes. Universidade de São Paulo. 2009.

CANDIDO, A. Literatura e Sociedade. São Paulo: Nova Cultural, 2000.

Os Parceiros do Rio Bonito. São Paulo: Editora Duas Cidades, 1971.

CÉZAR, I, S. O velado e o revelado: imagens da festa da congada. Programa de pósgraduação em antropologia social. Universidade de São Paulo. São Paulo. 2010. 
A congada e a câmera: ação afrodescendente e representação midiática. Programa de pós-graduação em artes. Campinas: Unicamp, 2005.

CANDIDO, A. Os Parceiros do Rio Bonito. São Paulo, SP: Livraria das Letras, 1973.

CHALHOUB, S. Machado de Assis Historiador. São Paulo: Companhia das Letraas, 2003.

Visões da Liberdade: Uma história das últimas décadas da escravidão na corte. São Paulo: Companhia das Letras, 2011.

A Força da Escravidão: ilegalidade e costume no Brasil oitocentista. São Paulo: Companhia das Letras, 2012.

CORREA, M. As Ilusões da Liberdade: a escola de Nina Rodrigues e a Antropologia do Brasil. Bragança Paulista: EDUSF, 1998.

DAMACENO, J. Os Segredos de Virginia: Estudo de Atitudes Raciais em São Paulo (1945-1955). Tese de Doutorado. Departamento de Antropologia. Pós-Graduação em Antropologia social. 2013.

DIXON, K \& BURDICK. Comparative Perspectives on Afro-Latin America. University Of Florida. 2012.

DELEUZE, G. Bergsonismo. São Paulo: Editora 34, 2008.

DELEUZE, G \& GUATTARI. Kafka: Por uma Literatura do Menor. Rio de Janeiro: Imago Editora LTDA, 1977

. Mil Platôs: Capitalismo e Esquizofrenia vol I. São Paulo: Editora 34, 2009.

Mil Platôs: Capitalismo e Esquizofrenia vol II. São Paulo: Editora 34, 2008.

. Mil Platôs: Capitalismo e Esquizofrenia vol III. São Paulo: Editora 34, 2008 b.

. O Anti-édipo. São Paulo: Editora 34, 2010.

. O que é Filosofia? São Paulo: Editora 34, 2009.

DIXON, KWAME \& BURDICK, JOHN. Comparative Perspectives on Afro-Latin America. University press of Florida. Gainesville; Tallahassee; Boca Raton; Pensacola; Orlando; Miami; Jacksonville; Ft. Myers Sarasota. 2013.

DURAES, M, A, A. De trem para Montes Claros": representações do sertão nortemineiro nas canções do grupo raízes. Programa de Pós-Graduação em História. Universidade federal de Uberlândia. 2010.

FANON, F. Pele Negra Máscaras Brancas. Salvador: EDUFBA, 2008.

FERNADES, F. O Negro no Mundo dos Brancos. EDUSP, São Paulo, SP, 2007. 
EDUSP, 1965a.

A Integração do Negro na Sociedade de Classes VOL I. São Paulo, SP: EDUSP, $1965 b$

A Integração do Negro na Sociedade de Classes VOL II. São Paulo, SP: Global, 2009.

A Investigação etnológica no Brasil e outros ensaios. São Paulo: Editora Mudanças Sociais no Brasil. São Paulo: Editora Global, 2008.

Ensaios sobre Sociologia Geral e Aplicada. São Paulo: Pioneira, 1960.

FOUCAULT, M. A Arqueologia do Saber. Rio de Janeiro: Forense Universitária, 2004.

Segurança, Território, População: curso College de France (1977-1978). São Paulo: Martins Fontes, 2008.

O Corpo Utópico, As Heterotopias. São Paulo: N-1 Edições, 2013.

GILROY, P. O Atlântico Negro. São Paulo: Editora 34, 2001.

GILROY, P. Against Race: imagining political culture beyond the color line. Belknap press. Cambridge Massachusetts. 2000.

. Postcolonial Melancholia. New York: Columbia University Press, 2004.

2007. Entre Campos: Nações, Culturas e o Fascínio da Raça. São Paulo: Anablume.

Darker Than Blue: On the Moral Economies of Black Atlantic Culture. Belknap press. Cambridge Massachusetts. 2010.

Smal Acts: Thougths on politics of the Black culture. London: Sepent's tail, 1993.

There Ain't no black in Union Jack. The Cultural Politics of Race and Nacion. Hutchinson. London. 1987.

GOMES, D, J Os Segredos de Virginia: Estudo de Atitudes Raciais em São Paulo (19451955). Tese de Doutorado. Programa de Pós-Graduação em Antropologia Social da Faculdade de Ciências e Letras da Universidade de São Paulo. 2013.

GOMES E SILVA, J. A. Escavações: Apontamentos Históricos da cidade de Pitangui. Frutal, 1893.

GONZAGA, O. Memória histórica de Paracatu. Uberaba: Jardim e cia, 1910.

HALL, STUART. The Facto of Blackness. Institute of Contemporary arts; Institute of International Visual Arts; Bay Press Seattle, 1996.

Da Diáspora. Belo Horizonte: Editora da UFMG, 2009.

Sertanias: Revista de Ciências Humanas e Sociais - ISSN: 2763-566X Volume 1, número 1, julho-dezembro de 2020. 
Identidade e Diferença: Perspectivas dos estudos culturais. Petrópolis: Editora Vozes, RJ, 2012.

A identidade cultural na Pós-Modernidade. Rio de Janeiro: DP\&A, 2011.

"Race, articulation ad socieities strutured in dominance". S/D.

HALL, S. \& CRITHER, C. \& JEFFERSON, T. \& CLARKE, J. \& ROBERTS, B. Policing the crisis: Mugging, the state, and law and order. London and Basingstoke: Macmillan press LTD, 1982.

HALL, S. Sociological theories: race and colonialism. England: Sydenhams Printers/ Poole, 1980.

HANCHARD, M. Orpheus and Power: the Mivimento Negro Of São Paulo and Rio de Janeiro. New Jersey: Princeton University Press, 1994.

HIRATA, D, V. Sobreviver na Adversidade: entre o Mercado e a vida. Programa de pósgraduação em sociologia. São Paulo: Universidade de São Paulo, 2010.

HONNETH, A. Luta Por Reconhecimento: A gramática moral dos conflitos sociais. São Paulo: Editora 34, 2003.

IANNI, O. As Metamorfoses do Escravo. São Paulo: Difusão Europeia, 1962.

Raças e Classes Sociais no Brasil. São Paulo: Civilização Brasileira, 1972.

MANNHEIM, K. Ideologia e Utopia. Rio de Janeiro: Zahar Editores, 1976.

. Ensaio de Sociologia Sistemática. São Paulo: Livraria Pioneira Editora, 1962.

. Sociologia da Cultura. São Paulo: Editora Perspectiva, 1974.

MARQUES, L. Por aí e por muito longe: dividas, migrações e os libertos de 1888. Rio de Janeiro: Apicuri, 2011.

MARTINS, P, G. Entre a Espada e a Coroa: Abolicionistas em conflitos políticos no imediato pós-abolição (1888-1889). Pós-graduação em Sociologia. Universidade de São Paulo. 2017.

MENDONÇA, JOSÉ. História de Uberaba. Academia de letras do Triangulo Mineiro. Uberaba, 1974.

MONTEIRO, E, P. Kalungas e Bovino curraleiro pé0duro: contribuições da pesquisa social. Programa de Pós-Graduação em Ciência Animal. Goiânia, 2013.

MOREIRA DA SILVA, A Caretagem como prática cultural: fé, negritude, e folia em Paracatú (MG) 1960-1980. Pós-Graduação em História. Universidade Federal de Uberlândia. 2005. 
Beneditos Amaros -Remanescentes Quilombolas de Paracatu. Memórias, Lutas e Práticas Culturais. Pós-Graduação em História. Universidade Federal de Uberlândia, 2012.

MOORE JUNIOR, B. As Origens Sociais da Ditadura e da Democracia: Senhores e Camponeses na Construção do Mundo Moderno. Lisboa: Edições Lisboa, 1966.

NABUCO, J. O Abolicionismo. São Paulo: Nova Cultural, 1999.

OLIVEIRA, M, I. O liberto, seu mundo e os outros. São Paulo. 1988.

PAIVA, E, F. "Escravos e Libertos nas Minas Gerais do século XVII - estratégias de Resistencia através dos testamentos. São Paulo: Annablume, 2000.

PARREIRA DA SILVA, V. Do chocalho ao bastão: processos educativos do terno de congado marinheiro de São Benedito. Programa de Pós-Graduação em Educação. UFSCar. São Carlos, 2015.

PAUla, ÁlVARo FERREIRA DE. Desbravadores do Carmo do Fructal: História e Genealogia de um descendente. Uberaba: Editora Victória, 2004.

PINHO, P, S. Reinvenções da África na Bahia. São Paulo, SP: Annalume, 2004.

Mama Africa: Reinventing blackess in Bahia. Durham and London: Duke University Press, 2010.

PONTES, HILDEBRANDO. História de Uberaba e a Civilização no Brasil Central Uberaba: Academia de letras do Triangulo Mineiro, 1978.

RANCIERE, J. O Desentendimento: política e fillosofia. São Paulo: Editora 34, 2008.

REZENDE, L, D. A história de Comendador Gomes: Cadê a história daqui? Araguari. 2014.

RIBEIRO JUNIOR, F. O Mundo do Trabalho na Ordem Republicana: a Invenção do Trabalhador nacional. Minas gerais 1888-1928. Pós-Graduação em História. Universidade de Brasilia, 2008.

"Dimensões da Liberdade: Borges Sampaio e os escravos na cidade de Uberaba", 1836/1888. Olhares \& Trilhas, ano VI. nº, 2005.

SAID, E, W. Orientalismo: o oriente como invenção do ocidente. São Paulo: Companhia de Bolso Companhia de Bolso, 2007.

Cultura e Imperialismo. São Paulo. Companhia de Bolso. São Paulo. 2011.

SALES, R, C. O Brasil na Economist. Pensando a Influência do perfil político-ideológico da revista na formação da imagem internacional do país. Programa de Pós-graduação em Política. Universidade Federal de São Carlos, 2016. 
SAMPAIO, BORGES. Uberaba: História, Fatos e Homens. Uberaba: Academia de letras do Triangulo Mineiro, 1971.

SCHWARCZ, L, M. O Espetáculo das Raças: Cientistas, Instituições e Questão Racial no Brasil 1870-1930. São Paulo: Companhia das letras, 1993.

Retrato em Branco e Negro: Jornais, escravos e cidadãos em São Paulo no Final do Século XIX. São Paulo: Companhia das letras, 1987.

Lima Barreto: Triste Visionário. São Paulo: Companhia das letras, 2017.

As Barbas do Imperador: D. Pedro II, Um monarca nos Trópicos. São Paulo: Companhia das Letras, 1998.

SCHWARCZ, L, M. \& STARLING, H. Brasil: Uma Biografia. São Paulo: Companhia das letras, 2017.

SILVA, M, A, M. A Descoberta do Insólito: Literatura Negra e Literatura Periférica no Brasil (1960-2000). Rio de Janeiro: Aeroplano, 2013.

SILVA, V. Quilombo de São Domingos: história e identidade étnica 1980-2010. Programa de pós-graduação em história. Brasília: Universidade de Brasília, 2010.

SILVERIO, V, R. Territórios Negros em Campinas: o Caso Vila Rica. Dissertação de Mestrado. Universidade Estadual de Campinas, Campinas, 1992.

SANTOS COTA, L, G. Ave, Libertas: Abolicionismos e Luta pela Liberdade em Minas Gerais na última década da Escravidão. Programa de Pós-Graduação em História Social. Niterói. 2013.

O Sagrado Direito da Liberdade: escravidão, liberdade e abolicionismo em Ouro Preto e Mariana (1871-1888). Programa de Pós-Graduação em História. Niterói. 2007.

SANTOS, J, R, M. Malandros sem Carnavais, Carnavais sem heróis: Juventude, Geração e sociabilidade entre jovens ligados ao Rap e ao Rock nas cidades de São Carlos, Ribeirão Preto e São José do Rio Preto. Universidade Federal de São Carlos São Carlos, SP, 2007.

"A Fixação do Sujeito em dissertações e teses sobre cultura caipira e Sertaneja". IV seminário Internacional do Programa de Pós-Graduação em Sociologia da UFSCar: Olhares e diálogos sociológicos sobre as mudanças no Brasil e na América Latina. De 26 a 28 de Agosto, São Carlos, SP, 2013. CD-ROOM.

Antes da República, sob o olhar do Império: a produção do modo de vida e invenção de uma territorialidade diaspórica: o caso de Frutal/Uberaba (MG). Tese (Doutorado de sociologia) Universidade Federal de São Carlos. São Carlos/SP, 2018.

SPIVAK, G. Pode o Subalterno Falar? Belo Horizonte: Editora da UFMG, 2010.

WILLIANS, R. Marxismo e Literatura. Rio de Janeiro: Zahar Editores, 1977. 
Cultura e Materialismo. São Paulo, SP: Editora da Unesp, 2011.

Política do Modernismo. São Paulo, SP: Editora da Unesp, 2011b.

O Campo e a cidade na história e na Literatura. São Paulo: Companhia das Letras, 2011.

A Produção da Escrita. São Paulo: Editora Unesp, 2014

Recursos da Esperança. São Paulo: Editora Unesp, 2015

Cultura. São Paulo: Paz e Terra, 2008.

Sertanias: Revista de Ciências Humanas e Sociais - ISSN: 2763-566X

Volume 1, número 1, julho-dezembro de 2020. 